\title{
Sorption Behavior of Dye Compounds onto Natural Sediment of Qinghe River
}

\author{
Ruixia Liu, ${ }^{*, 1}$ Xingmin Liu, ${ }^{*} \dagger$ Hongxiao Tang, ${ }^{*}$ and Yongbo Su $\dagger$ \\ * State Key Laboratory of Environmental Aquatic Chemistry, Research Center for Eco-Environmental Sciences, Chinese Academy of Sciences, \\ P.O. Box 2871, Beijing 100085; and †Chemical Department, Northeast University, Shenyang 110006, People's Republic of China
}

Received December 21, 2000; accepted April 2, 2001

The objective of this study is to assess the adsorption behavior of C.I. Basic Yellow X-5G L, C.I. Basic Red 13, C.I. Direct Blue 86, C.I. Vat Yellow 2, and C.I. M ordant B lack 11 on natural sediment and to identify sediment characteristics that play a predominant role in the adsorption of the dyes. The potentiometric titration experiment is used to investigate acid-base properties of the sediment surface with a constant capacitance surface complexation model. The parameters controlling the sorption such as solution $\mathrm{pH}$ and ion strength, as well as the influence of organic carbon and $\mathrm{Ca}^{2+}$ ion on the adsorption, are evaluated. It is shown that the titration data can be successfully described by the surface protonation and deprotonation model with the least-squares FITE QL program 2.0. The sorption isotherm data are fitted to the $F$ reundlich equation in a nonlinear form (1/n=0.3-0.9) for all tested dyes. With increasing $\mathrm{pH}$ value, the sorption of C.I. Mordant B lack 11 and C.I. D irect B lue 86 on the sediment decreases, while for C.I. Basic Yellow X5G L and C.I. B asic Red 13, the extent of sorption slightly increases. In addition, ion strength also exhibits a considerably different effect on the sorption behavior of these dye compounds. The addition of $\mathrm{Ca}^{2+}$ can greatly reduce the sorption of C.I. Basic Red 13 on the sediment surface, while it enhances the sorption of C.I. Direct B lue 6. Theremoval of organic carbon decreases the sorption of $C$.I. Mordant Black 11 and C.I. Direct Blue 86. In contrast, the sorption of C.I. Basic Red 13 and C.I. Basic Yellow X-5G L is obviously enhanced after the removal of organic carbon. The differences in adsorption behavior are mainly attributed to the physicochemical properties of these dye compounds. 2001 Academic Press

Key Words: natural sediment; acid-base properties; sorption; effect factors; dye compounds.

\section{INTRODUCTION}

In natural aquatic systems, sorption processes play a dominant role in the transport and ultimate fate of pollutants. Thus, the adsorption behavior of organic contaminants on natural particles has been of central interest in recent years (1-5). Pignatello

\footnotetext{
${ }^{1}$ To whom correspondence should be addressed. Fax: 00-86-10-62923543. E-mail: Rachel@mail.rcees.ac.cn.
}

and Xing (6) as well as Luthy et al. (7) have reviewed the sorption/desorption of organic compounds on the natural particles. Numerous studies have been devoted to sorption kinetics (811), equilibrium modeling, and mechanism (12-17), as well as to the factors that affect adsorption (18-20). It has been shown that the sorption of low-polarity, nonpolar, and nonionic organic compounds onto natural particles occurs largely by the partition of these compounds to organic matter involved in the solid (16, 21-23), and the interface behavior of ionic organic compounds is controlled mainly by the specific chemical and electrostatic interactions (24-28).

Dyes are widely used for textiles, printing, and dyeing, as well as in the food and paper-making industries. In 1988, dye output achieved 146 thousand tons in China (29). Environment researchers have paid special attention to dye compounds because of the extensive environmental contamination arising from dyeing operations. Most studies have focused on the development of a treatment technique and method for dye wastewater, such as a physical-chemical technique destroying the color groups $(30,31)$, a biodegradation process mineralizing the colorless organic intermediates $(32,33)$, and chemical oxidation including homogeneous oxidation (34) and heterogeneous photocatalytic oxidation (35-37). However, because of its higher organic concentration, particular toxicity, complex composition, and poor degradability, dye wastewater cannot be efficiently purified and treated. Thus, a large amount of wastewater containing dye compounds in low concentrations may be leaked and released into natural waters, leading to aquatic environmental contamination. The dye compounds may accumulate in sediments at many sites, especially at wastewater discharge, and their toxicity to humans and to aquatic life results in an impact on the ecological balance in the aquatic system.

Accordingly, this study elucidates the factors of solution chemistry, sediment composition, and acid-base characteristics influencing the sorption of dye compounds. The sorption behavior of individual dye compounds on the sediment, as a function of the dye concentration, $\mathrm{pH}$ value, and ion strength, is described in detail. The influence of the $\mathrm{Ca}^{2+}$ ion and sediment organic matter is also investigated. 


\section{EXPERIMENTAL SE CTION}

\section{Materials}

The dye compounds in this study, C.I. Basic Yellow X-5GL, C.I. Basic Red 13, C.I. Direct Blue 86, C.I. Vat Yellow 2, and C.I. Mordant Black 11, were purchased from Chinese Knitting Mill. The dye molecular structures and maximum absorption wavelengths $(\lambda)$ in the visible light range are presented in Fig. 1. A stock solution $(1000 \mathrm{mg} / \mathrm{L})$ of the dye was prepared with deionized water and was further diluted to various concentrations during the experimental process.

The surface sediment samples from 0 to $20 \mathrm{~cm}$ were collected from Qinghe River (Beijing, China). The sediments were relatively contaminated by anthropogenic organic wastes. After being washed with deionized water, the sediment samples were air-dried, homogenized, and passed though 200-mesh stainless steel sieves. The specific surface area of the sediment sample was determined by the $\mathrm{N}_{2}$ /BET adsorption method (ASAP-2000). The organic carbon contents involved in the sediment were measured by the potassium dichromate oxidation method. An Xray diffraction spectrometer (Model D/Max-RC) and an X-ray fluorescence spectrometer (Model 3080) were used to analyze the clay mineral and element composition, respectively. These physicochemical characteristics of the sediment are listed in Table 1 . The sediment stock suspension was prepared by adding $10 \mathrm{~g}$ of sediment to $1 \mathrm{~L}$ of deionized water and stored in a refrigerator for 2 weeks prior to potentiometric titration and adsorption experiments.

\section{Acid-Base Titration}

A certain volume of $10 \mathrm{~g} / \mathrm{L}$ sediment stock suspension was added to a 100-mL flask, and the ionic strength of the suspensions was adjusted with $1 \mathrm{~mol} / \mathrm{L} \mathrm{NaNO}_{3}$. The initial volume of the suspension was diluted to $80 \mathrm{~mL}$. The suspension was stirred magnetically and continually bubbled with $\mathrm{N}_{2}$ purified successively through $10 \% \mathrm{NaOH}, 10 \% \mathrm{H}_{2} \mathrm{SO}_{4}$, distilled water, and $0.1 \mathrm{~mol} / \mathrm{L} \mathrm{NaNO}_{3}$ to purge $\mathrm{CO}_{2}$ until the electrode potential was stable. Afterward, $\mathrm{HNO}_{3}$ was added to make the suspension $\mathrm{pH}$ value lower than 3 , and the back titration process was carried out with the addition of $0.04551 \mathrm{~mol} / \mathrm{L} \mathrm{NaOH}$ in increments of $0.1 \mathrm{~mL}$ until the $\mathrm{pH}$ of the suspension reached 10.00. During the

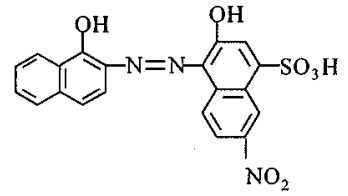

(a) $\lambda=522 \mathrm{~nm}$

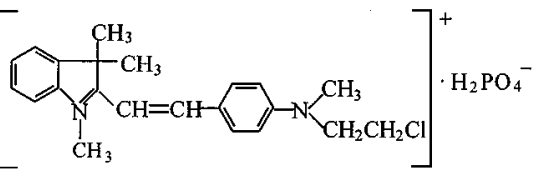

(c) $\lambda=524 \mathrm{~nm}$

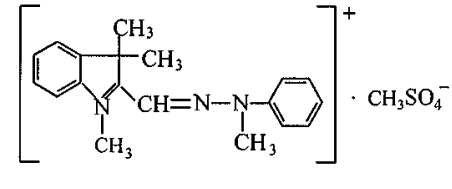

(b) $\lambda=424 \mathrm{~nm}$

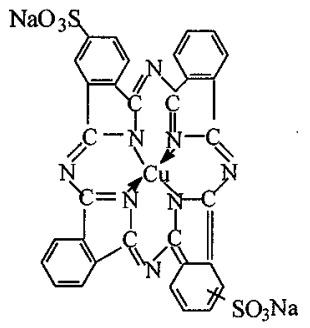

(d) $\lambda=622 \mathrm{~nm}$

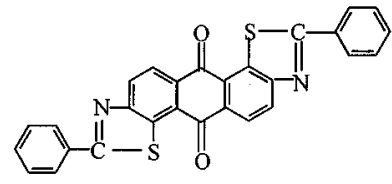

(e) $\lambda=424 \mathrm{~nm}$

FIG. 1. Chemical structure of dye compounds (a) C.I. Mordant Black 11, (b) C.I. Basic Yellow X-5GL, (c) C.I. Basic Red 13, (d) C.I. Direct Blue 86, and (e) C.I. Vat Yellow 2.

titration procedure, the drift of the measured potential should be below $1 \mathrm{mV} / \mathrm{h}$ and the temperature kept at $25 \pm 0.5^{\circ} \mathrm{C}$. The reference blank was prepared in the same manner as the sample. The acidic suspension with $\mathrm{HNO}_{3}$ was centrifuged at 10,000 rpm for $30 \mathrm{~min}$. The acidic supernatants as system blanks were obtained and titrated.

\section{Adsorption Experiment}

The sorption of dye compounds on the sediment was carried out by a batch technique as a function of $\mathrm{pH}$ value, ion strength, and dye concentration. The sediment stock suspension (10 or

TABLE 1

Physicochemical Characters of the Sediment ${ }^{a}$

\begin{tabular}{|c|c|c|c|c|c|c|c|c|c|}
\hline \multirow[b]{2}{*}{ Type of mineral } & \multicolumn{9}{|c|}{ Clay mineral composition (semi-quantitative) } \\
\hline & & Quartz & & Feldspar & Calcite & Dolomite & Chlorite & Illite & Amphibole \\
\hline \multirow[t]{2}{*}{ Content $(\%)$} & & 20 & & 25 & 10 & 10 & 10 & 20 & 5 \\
\hline & \multicolumn{9}{|c|}{ Element composition } \\
\hline Element & $\mathrm{SiO}_{2}$ & & $\mathrm{Al}_{2} \mathrm{O}_{3}$ & $\mathrm{TFe}_{2} \mathrm{O}_{3}$ & $\mathrm{CaO}$ & $\mathrm{MgO}$ & $\mathrm{Na}_{2} \mathrm{O}$ & $\mathrm{MnO}$ & $\mathrm{K}_{2} \mathrm{O}$ \\
\hline \multirow[t]{2}{*}{ Content $(\%)$} & 52.52 & & 10.99 & 3.57 & 7.00 & 2.530 & 1.610 & 0.0602 & 1.881 \\
\hline & \pm 0.16 & & \pm 0.03 & \pm 0.01 & \pm 0.02 & \pm 0.008 & \pm 0.005 & \pm 0.0002 & \pm 0.006 \\
\hline
\end{tabular}

\footnotetext{
${ }^{a}$ Organic carbon content (\%): $11.32 \pm 0.11$. Specific surface area $\left(\mathrm{m}^{2} / \mathrm{g}\right) 6.28 \pm 0.17$.
}

${ }^{b}$ Total $\mathrm{Fe}$, including $\mathrm{Fe}(\mathrm{II})$ and $\mathrm{Fe}(\mathrm{III})$, expressed as $\mathrm{Fe}_{2} \mathrm{O}_{3}$. 
$25 \mathrm{~mL}$ ) was placed in a series of 250-mL plastic bottles, followed by addition $0.02 \%$ (by weight) of sodium azide that is used to inhibit bacterial growth. Then an appropriate volume of dye stock solution was added to make the dye concentration in the range 25-100 mg/L. Reagent-grade $\mathrm{HNO}_{3}$ and $\mathrm{NaOH}$ were used to adjust the suspension $\mathrm{pH}$ value between 2 and 11. The ion strength was adjusted by $1 \mathrm{~mol} / \mathrm{L} \mathrm{NaNO}_{3}$ electrolyte solution. The total suspension volume was diluted to $50 \mathrm{~mL}$ with deionized water. Each reaction sample was equilibrated at $30 \pm 1{ }^{\circ} \mathrm{C}$ on an orbital shaker for $12 \mathrm{~h}$ according to the preliminary experiment of adsorption kinetics. After centrifugation at 10,000 rpm for $30 \mathrm{~min}$, the supernatant was separated from the solid sediment phase. A part of the supernatant was taken for determination of dye concentration by using a U-3010 spectrophotometer, and the remaining part was used to measure the equilibration $\mathrm{pH}$ value.

\section{Effect of $\mathrm{Ca}^{2+}$ on Sorption of Dyes}

$\mathrm{Ca}^{2+}$ is one of more common ions in natural water. Therefore, the test was performed in the same way as that in the above sorption experiment, but prior to the test, $0.1 \mathrm{~mol} / \mathrm{L}$ of $\mathrm{CaCl}_{2}$ was added to the slurries of sediments to investigate the competitive sorption behavior between the dye compounds and the $\mathrm{Ca}^{2+}$ ion.

\section{Effect of Organic Carbon on Sorption of Dyes}

In this experiment, sediment organic matter was removed by adding $300 \mathrm{~mL}$ of $\mathrm{H}_{2} \mathrm{O}_{2}$ to $100 \mathrm{~g}$ of the dried sediment sample, which was placed at room temperature for $2 \mathrm{~h}$, and then heated to $70^{\circ} \mathrm{C}$ for $1 \mathrm{~h}$. This treatment was repeated four times, and the sediments were rinsed with deionized water and dried. After $\mathrm{H}_{2} \mathrm{O}_{2}$ treatment, the sediment organic carbon showed a removal of $80-90 \%$. The adsorption experiments with $\mathrm{H}_{2} \mathrm{O}_{2}$-treated sediments were carried out as described above.

\section{RESULTS AND DISCUSSION}

\section{Surface Acid-Base Properties}

The natural sediment surface can be considered to be an amphoteric surface site with surface hydroxyl groups $(\equiv \mathrm{XOH})$, which can be generally represented by the following protonation and deprotonation reactions:

$$
\begin{aligned}
\equiv \mathrm{XOH}_{2}^{+} & =\equiv \mathrm{XOH}+\mathrm{H}^{+}, \\
K_{\mathrm{a} 1} & =[\equiv \mathrm{XOH}]\left[\mathrm{H}^{+}\right] /\left[\equiv \mathrm{XOH}_{2}^{+}\right] \\
\equiv \mathrm{XOH} & =\equiv \mathrm{XO}^{-}+\mathrm{H}^{+}, \\
K_{\mathrm{a} 2} & =\left[\equiv \mathrm{XO}^{-}\right]\left[\mathrm{H}^{+}\right] /[\equiv \mathrm{XOH}] .
\end{aligned}
$$

Potentiometric titration provides a measure of the sequential binding of the proton by the surface functional groups of sediment. The total concentration of surface sites $\left(H_{\mathrm{S}}, \mathrm{mol} / \mathrm{L}\right)$ on the sediment can be obtained by using the in situ Gran plot method (38-40), plotting Gran function $(G)$ versus the volume of added strong base $\left(V_{\mathrm{B}}\right)$. For the hydroxide back titration, Gran functions are expressed as

$$
\begin{aligned}
\text { acidic side: } G & =\left(V_{0}+V_{\mathrm{AT}}+V_{\mathrm{B}}\right) \times 10^{E / 59.175} \\
\text { alkaline side: } G & =\left(V_{0}+V_{\mathrm{AT}}+V_{\mathrm{B}}\right) \times 10^{-E / 59.175},
\end{aligned}
$$

where $V_{0}$ is the initial volume of suspension $(\mathrm{mL}), V_{\mathrm{AT}}$ is the total volume of strong acid added $(\mathrm{mL})$, and $E$ is the potential of the glass electrode $(\mathrm{mV})$. On the basis of the linear regression analysis of Gran plots, the two equivalence points for each suspension $\left(V_{\mathrm{e} 1}\right.$ and $\left.V_{\mathrm{e} 2}\right)$ or for the blank system $\left(V_{\mathrm{e}^{\prime} 1}\right.$ and $\left.V_{\mathrm{e}^{\prime} 2}\right)$, which are the intercepts at the $V$ axis in acidic and alkaline side, are obtained. Figure 2 shows the Gran plot of a $5 \mathrm{~g} / \mathrm{L}$ suspension and the relative acidic blank system in $0.01 \mathrm{~mol} / \mathrm{L} \mathrm{NaNO}_{3}$. Thus, the $H_{\mathrm{S}}$ value can be estimated by the equation

$$
H_{\mathrm{S}}=\left[\left(V_{\mathrm{e} 2}-V_{\mathrm{e} 1}\right) \times C_{\mathrm{B}}-\left(V_{\mathrm{e}^{\prime} 2}-V_{\mathrm{e}^{\prime} 1}\right) \times C_{\mathrm{B}}\right] / V_{0},
$$

where $C_{\mathrm{B}}$ is the concentration of added base.

Furthermore, the constant capacitance model has been used to determine the surface acidic constants of the natural particle.
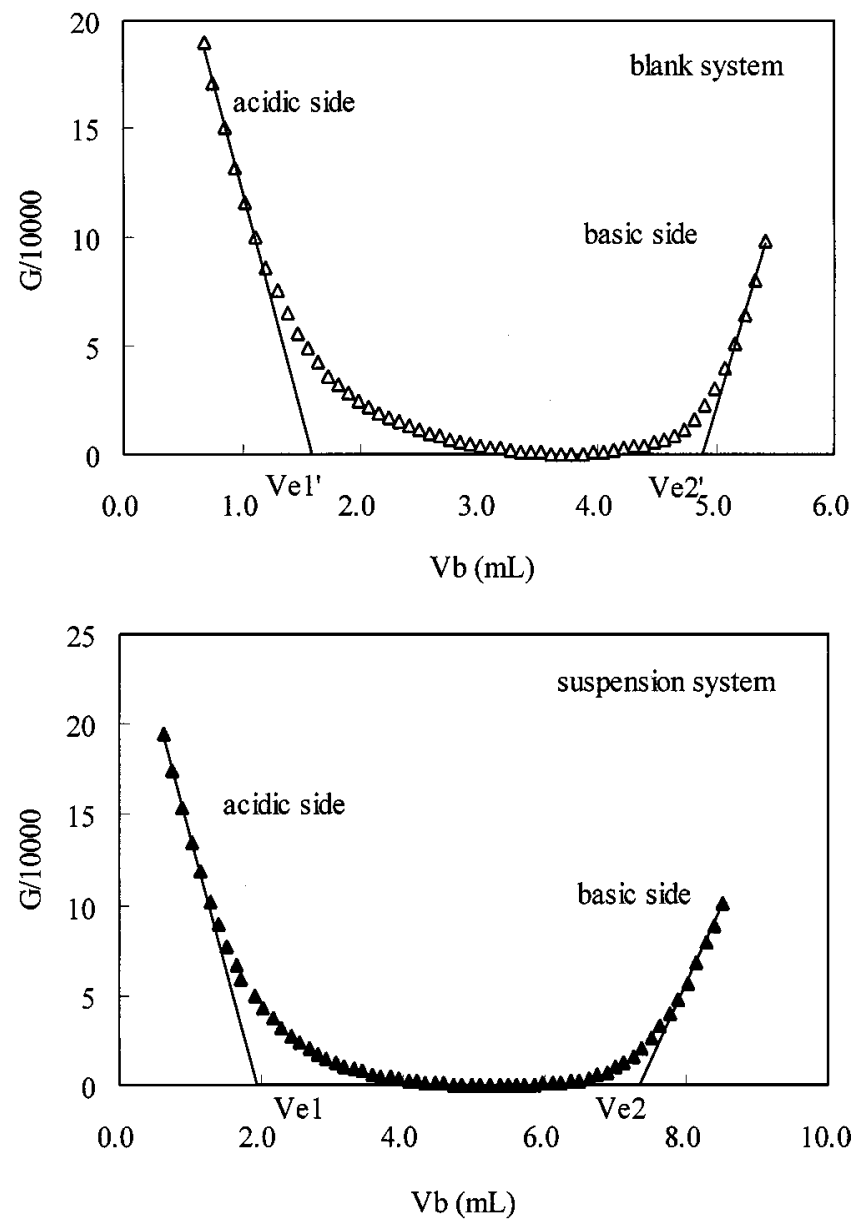

FIG . 2. Gran plots for a $5 \mathrm{~g} / \mathrm{L}$ suspension and a blank system in $0.01 \mathrm{~mol} / \mathrm{L}$ $\mathrm{NaNO}_{3}$ 
Theoretically, only one plane in the interfacial region for the adsorption of $\mathrm{H}^{+}, \mathrm{OH}^{-}$, and all specifically adsorbed solutes is considered, and all of the specific adsorbed ions are arranged as inner-sphere complexes by the surface coordination reactions in this model. The surface charge $\left(\rho_{0}\right)$-potential $\left(\psi_{0}\right)$ relationship used in the model is $\rho_{0}=C \psi_{0}$, where $C$ is the electric capacity of particle-water interface. The electrical double layers are Helmholtz, like a parallel plate capacitor $(41,42)$. In the model calculations, an electric capacity $(C)$, two intrinsic acidic constants ( $K_{\mathrm{a} 1}$ and $K_{\mathrm{a} 2}$ ), and the total concentration of surface sites $\left(H_{\mathrm{S}}\right)$ are arranged as adjustable parameters. The potentiometric titration data sets, in the format of TOTH (total concentration of reacted proton) vs $\mathrm{pH}$, are input into the FITEQL 2.0 program with a nonlinear least-squares optimization procedure (43), in which TOTH can be calculated by the calibration of the zero titration point $\left(V_{\mathrm{e} 1}\right)$ :

$$
\mathrm{TOTH}=-\left(V_{\mathrm{B}}-V_{\mathrm{e} 1}\right) \times C_{\mathrm{B}} /\left(V_{0}+V_{\mathrm{AT}}+V_{\mathrm{B}}\right) \quad(\mathrm{mol} / \mathrm{L}) .
$$

Then, by changing electric capacity $C$ values, the best fit is achieved. The surface acidic constants and the optimized total concentration of surface sites for sediment suspension in different electrolyte concentrations are listed in Table 2. As we can see, the $H_{\mathrm{S}}$ values estimated and optimized are of the same order of magnitude, and for the two calculations in 0.01 and $0.5 \mathrm{~mol} / \mathrm{L}$ $\mathrm{NaNO}_{3}$ systems, the values of overall variance $\left(V_{\mathrm{Y}}\right)$, which are the indicators of the goodness of fit, are respectively 44.82 and 53.10, and the standard deviations $(\sigma)$ for optimized parameters are within 0.0397 . This result shows that the protonation and deprotonation reactions model can successfully describe the acid-base behavior of the natural sediment surface. In turn, the derived parameters are incorporated into the models to reproduce a titration curve as shown in Fig. 3. It is obvious that the sediment sample is negatively charged over a large $\mathrm{pH}$ range, and model calculation results match well with the experimental results.

TABLE 2

Surface A cid-B ase C haracteristic Parameters of the Sediment

\begin{tabular}{lcc}
\hline & \multicolumn{2}{c}{ System $(5 \mathrm{~g} / \mathrm{L}$ particle $)$} \\
\cline { 2 - 3 } \multicolumn{1}{c}{ Parameter } & $0.01 \mathrm{~mol} / \mathrm{L} \mathrm{NaNO}_{3}$ & $0.5 \mathrm{~mol} / \mathrm{L} \mathrm{NaNO}_{3}$ \\
\hline Estimated $H_{\mathrm{S}}(\mathrm{mol} / \mathrm{L})^{a}$ & $1.196 \times 10^{-3}$ & $1.151 \times 10^{-3}$ \\
$C\left(\mathrm{~F} / \mathrm{m}^{2}\right)$ & 23.25 & 35.01 \\
$K_{\mathrm{a} 1}$ & 3.286 & 2.917 \\
$K_{\mathrm{a} 2}$ & 3.925 & 3.751 \\
Optimized $\mathrm{H}_{\mathrm{S}}(\mathrm{mol} / \mathrm{L})$ & $2.893 \times 10^{-3}$ & $2.728 \times 10^{-3}$ \\
$V_{\mathrm{y}}$ & 44.82 & 53.10 \\
$\sigma_{H_{\mathrm{S}}}$ & $1.838 \times 10^{-5}$ & $1.912 \times 10^{-5}$ \\
$\sigma_{\mathrm{p} K_{\mathrm{a} 1}}$ & $3.681 \times 10^{-2}$ & $3.970 \times 10^{-2}$ \\
$\sigma_{\mathrm{p} K_{\mathrm{a} 2}}$ & $2.775 \times 10^{-2}$ & $2.433 \times 10^{-2}$ \\
\hline
\end{tabular}

${ }^{a}$ Values are estimated from Eq. 5.

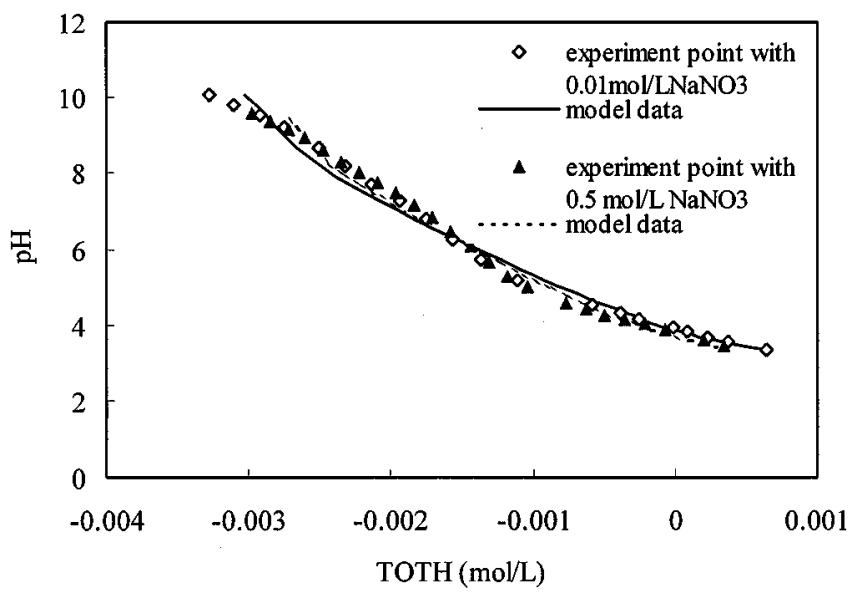

FIG. 3. Model curves of the potentiometric titration for the sediment suspension and the corresponding experimental data.

\section{Sorption Isotherm}

The adsorption isotherms of the dye compounds are shown in Fig. 4. Equilibrium sorption data are calculated based on the Freundlich model,

$$
C_{\mathrm{s}}=K_{\mathrm{f}} C_{\mathrm{w}}^{1 / n}
$$

where $K_{\mathrm{f}}$ and $1 / n$ are the Freundlich sorption coefficient and the Freundlich exponent, respectively, and $C_{\mathrm{s}}(\mathrm{mg} / \mathrm{g})$ and $C_{\mathrm{w}}$ $(\mathrm{mg} / \mathrm{L})$ denote the concentration in the solid and in the aqueous phase, respectively. The relative sorption parameters of the studied dyes on the sediment are summarized in Table 3. It is shown that, over the range of dye concentrations studied, all experimental data are fitted very well by the nonlinear Fruendlichtype sorption isotherm, and the regression coefficients $\left(R^{2}\right)$ are $0.94-0.99$. This nonlinearity of sorption behavior is mainly attributed to organic and mineral matrices involved in sediment.

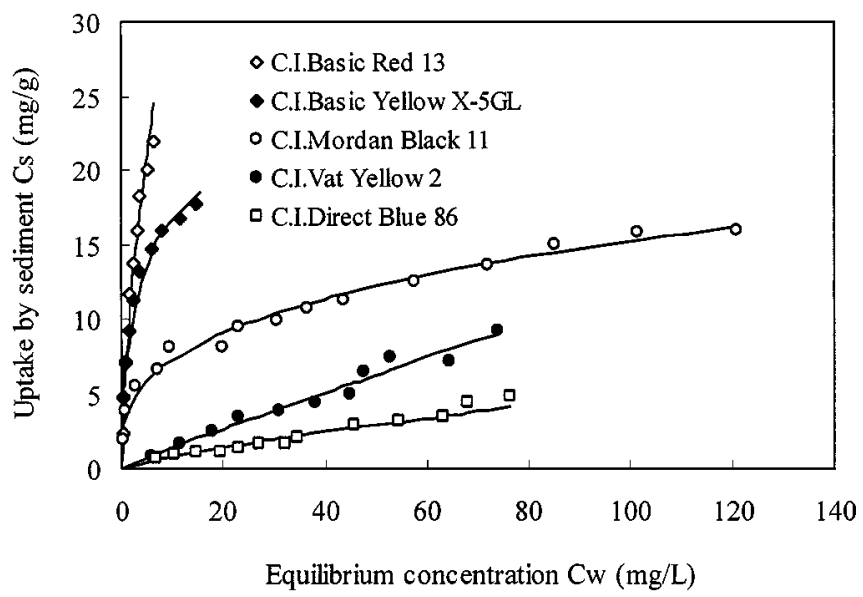

FIG . 4. Adsorption isotherms of dye compounds on the sediment (experimental conditions: ionic strength, $0.01 \mathrm{~mol} / \mathrm{L}$; particle concentration, $5 \mathrm{~g} / \mathrm{L} ; \mathrm{pH}$, 6-7). 
TABLE 3

Sorption Parameters of Dye Compounds on Sediment

\begin{tabular}{lcccc}
\hline \multicolumn{1}{c}{ Dye } & $\begin{array}{c}\text { Freundlich coeff } \\
K_{\mathrm{f}}(\mathrm{mg} / \mathrm{L} \cdot \mathrm{mg} / \mathrm{g})\end{array}$ & $\begin{array}{c}\text { Freundlich } \\
\text { exponent 1/n }\end{array}$ & $r^{2}$ & $K_{\mathrm{oc}}$ \\
\hline C.I. Mordant Black 11 & 3.48 & 0.319 & 0.972 & 30.8 \\
C.I. Basic Yellow X-5GL & 7.04 & 0.386 & 0.941 & 62.3 \\
C.I. Basic Red 13 & 7.01 & 0.687 & 0.981 & 62.0 \\
C.I. Direct Blue 86 & 0.120 & 0.812 & 0.950 & 1.06 \\
C.I. Vat Yellow 2 & 0.162 & 0.932 & 0.985 & 1.43 \\
\hline
\end{tabular}

As for their sorption on sediment, dye compounds can be divided into two groups. One is C.I. Mordant Black 11, C.I. Basic Yellow X-5GL, and C.I. Basic Red 13, which have extremely nonlinear sorption isotherms $(1 / n=0.32-0.69)$ and relatively high sorption coefficients $\left(K_{\mathrm{f}}=3.5-7.0\right)$. The other group is C.I. Direct Blue 86 and C.I. Vat Yellow 2, showing only minor sorption coefficients $\left(K_{\mathrm{f}}=0.12-0.16\right)$ and almost linear isotherms $(1 / n=0.81-0.93)$.

The distribution coefficient $\left(K_{\mathrm{d}}\right)$ denotes a concentration ratio of the adsorbed amount in solid sediment and the concentration in solution at equilibrium:

$$
K_{\mathrm{d}}=C_{\mathrm{s}} / C_{\mathrm{w}} .
$$

For nonlinear sorption isotherms, $K_{\mathrm{d}}$ is a function of the solute concentration $\left(K_{\mathrm{d}}=K_{\mathrm{f}} C_{\mathrm{w}}^{1 / n-1}\right)$ and equals $K_{\mathrm{f}}$ at an aqueous concentration of $1 \mathrm{mg} / \mathrm{L}$. The sorption coefficient normalized by the organic carbon content $\left(K_{\mathrm{oc}}\right)$ can be calculated on the basis of the fraction of organic carbon $C_{\text {org }}$ and $K_{\mathrm{f}}$ at an aqueous concentration of $1 \mathrm{mg} / \mathrm{L}$ :

$$
K_{\mathrm{oc}}=K_{\mathrm{f}} / C_{\mathrm{org}}
$$

The $K_{\mathrm{oc}}$ values for the dye compounds are also listed in Table 3. The sorption of the dyes on the sediment can be explained by three primary driving forces: hydrophobic exclusion of aromatic cyclic and alkyl compounds, specific chemical interaction of functional groups such as sulfonate with the sediment, and electrostatic interaction of the charged solute molecule with the charged sediment surface. On the basis of the $K_{\mathrm{oc}}$ values (see Table 3), the hydrophobic interaction is likely to be more important for C.I. Direct Blue 86, C.I. Vat Yellow 2, and C.I. Mordant Black 11 than for C.I. Basic Yellow X-5GL and C.I. Basic Red 13.

\section{Effect of pH on Sorption of Dye Compounds}

The effect of $\mathrm{pH}$ on the sorption of dye compounds is shown in Fig. 5. It is observed that the extent of sorption for C.I. Mordant Black 11 and C.I. Direct Blue 86 decreases with increasing $\mathrm{pH}$ values. For the sorption of C.I. Basic Yellow X5GL and C.I. Basic Red 13, a slight increase is found with increasing $\mathrm{pH}$ values and the adsorption percentage approaches $80-90 \%$ of added dyes in the studied $\mathrm{pH}$ range. Generally, the $\mathrm{pH}$ dependence of sorption for organic compounds onto natu- ral aquatic particles can be attributed to specific $\mathrm{pH}$-dependent reactions containing surface complexation or ligand exchange, electrostatic interactions resulting from surface charge, and the hydrophobic effect (44). It is well known that the unbound surface species $(\equiv \mathrm{XOH})$ can be formed on the natural sediment surface. The ion-exchange reaction of C.I. Mordant Black 11 and C.I. Direct Blue 86 as anion dye species $\left(\mathrm{RSO}_{3}^{-}\right)$with $\mathrm{OH}^{-}$ of $\equiv \mathrm{XOH}$ may occur through the following equilibrium (45):

$$
\equiv \mathrm{XOH}+\mathrm{RSO}_{3}^{-}=\equiv \mathrm{XOSO}_{2} \mathrm{R}+\mathrm{OH}^{-} \text {. }
$$

Obviously, an increasing $\mathrm{pH}$ value reduces the ion-exchange competition of the anion $\mathrm{RSO}_{3}^{-}$with the $\mathrm{OH}^{-}$of $\equiv \mathrm{XOH}$, thereby decreasing the adsorption possibility of the dye anion on the sediment. Moreover, with a decreasing $\mathrm{pH}$ value, the fraction of neutral dye species increases, which enhances the hydrophobic effect of the dye compounds from the bulk solution, leading to an increased adsorption.

It is remarkably noted from acid-base titration experiments that the sediment surface is negatively charged in a wide $\mathrm{pH}$ range. With increasing $\mathrm{pH}$ values, the adsorption of C.I. Basic
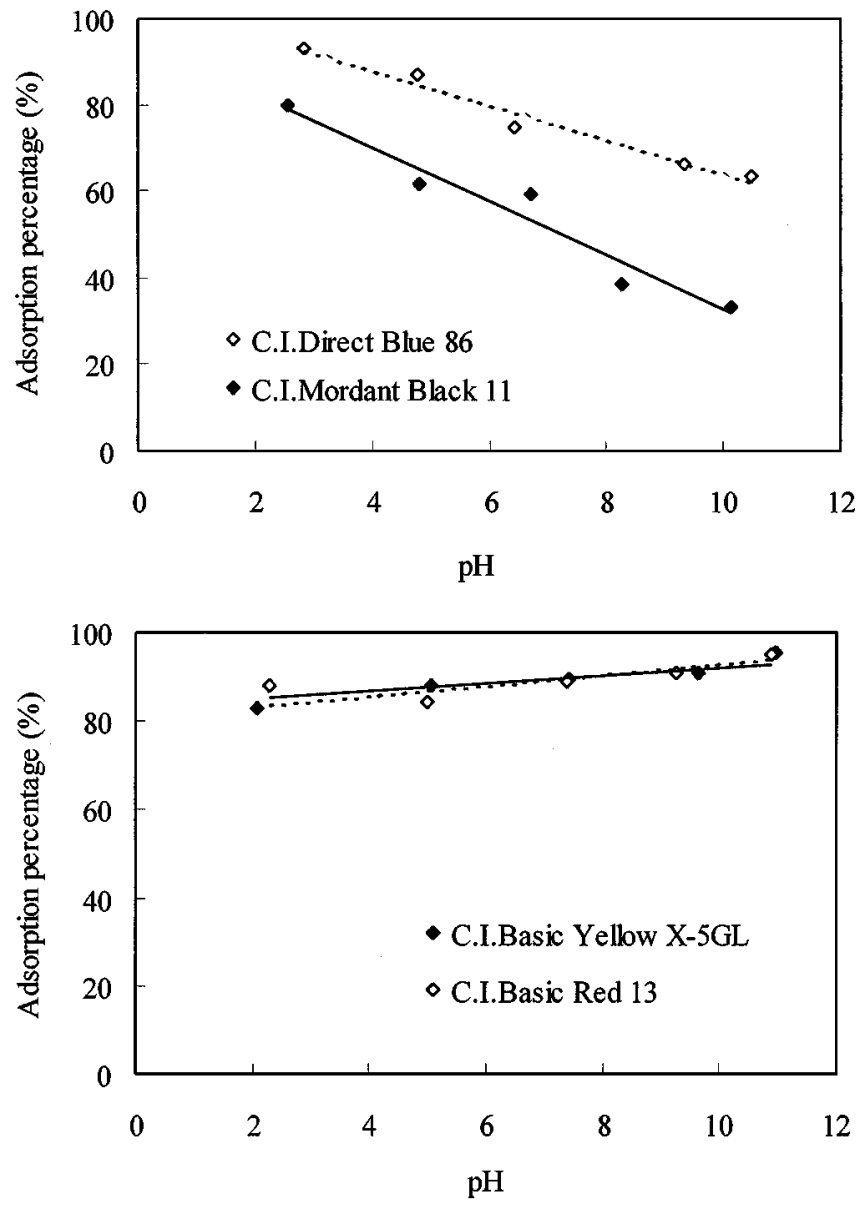

FIG. 5. Effect of $\mathrm{pH}$ value on the sorption of dye compounds (experimental conditions: ionic strength, $0.01 \mathrm{~mol} / \mathrm{L}$; particle concentration, $5 \mathrm{~g} / \mathrm{L}$; initial concentration of dye, $25-100 \mathrm{mg} / \mathrm{L}$ ). 
Yellow X-5GL and C.I. Basic Red 13 onto the sediment tends to increase, which can be explained by the electrostatic interaction of dye cationic species with the negatively charged surface. The electrostatic attraction force of the dye compounds with the sediment surface is likely to be raised when the $\mathrm{pH}$ value increases.

\section{Effect of Ionic Strength on Sorption of Dye Compounds}

As shown in Fig. 6, the effect of ionic strength on the adsorption of dye compounds onto the sediment can be divided into three types. One type is that the ionic strength promotes the adsorption of C.I. Vat Yellow 2 on the sediment. On the basis of the surface chemistry theory, when dye molecules approach the sediment particle surface, the two phases are surrounded by an electric double layer due to electrostatic interactions. As a result of increasing the concentration of the electrolyte, the thickness of the diffuse double layer can be significantly compressed; thus the van der Waals forces become remarkable, leading to an increase of the sorption for C.I. Vat Yellow 2 on the particle surface. Furthermore, as the solubility of the dye compound decreases with increasing ionic strength, the increased adsorption at a higher ionic strength can also be explained by an increase of the hydrophobic effect. The second type is that the ionic strength inhibits the adsorption of C.I. Basic Yellow X-5GL, C.I. Basic Red 13, and C.I. Direct Blue 86 on the sediment. The decreased sorption of the dyes at higher ionic strength can be attributed to the cation exchange of C.I. Basic Red 13 and C.I. Basic Yellow X-5GL with the particle surface, as well as to the ligand exchange mechanism of C.I. Direct Blue 86 with the natural organic anion ligands. Electrolyte ions such as $\mathrm{Na}^{+}$and $\mathrm{NO}_{3}^{-}$ at higher concentrations may be adsorbed onto the particle surface by competing exchange sites with dye molecules. Thus the amount of dye exchanged on the particle surface is likely to be reduced. The third type is that, with increasing ionic strength, the sorption percentage for C.I. Mordant Black 11 decreases first in the lower ionic strength range, and then goes up. This behavior

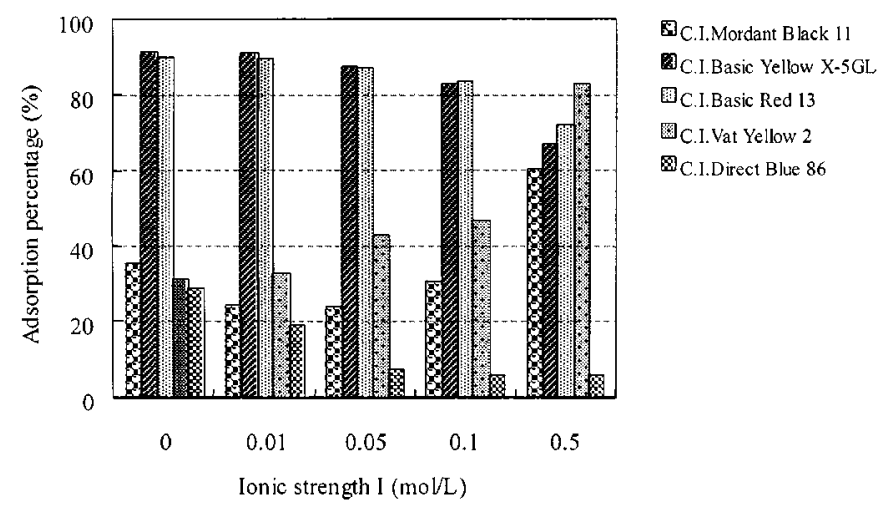

FIG. 6. Effect of ionic strength on the sorption of dye compounds onto sediment (experimental conditions: particle concentration, $5 \mathrm{~g} / \mathrm{L}$; initial concentration of dye, 25-100 mg/L; pH, 6-7).

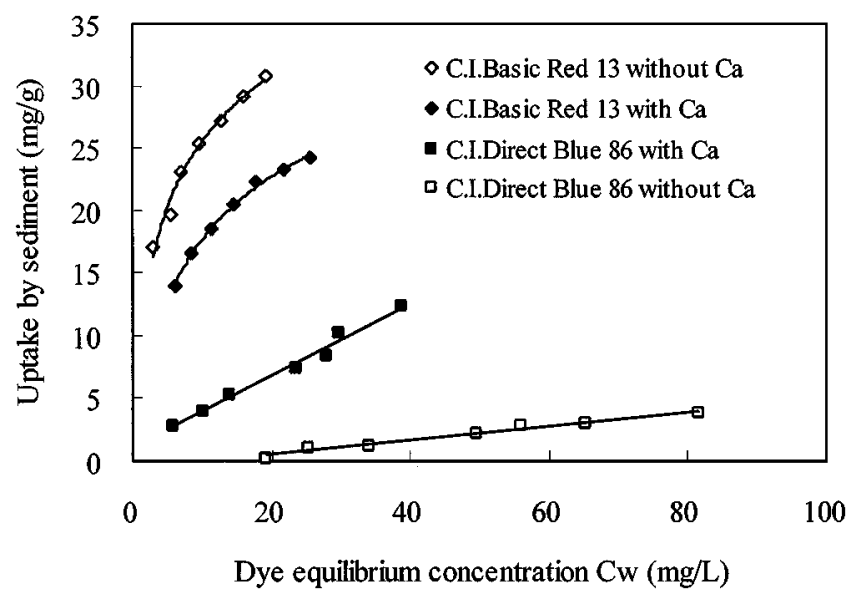

FIG. 7. Effect of added $\mathrm{Ca}^{2+}$ on the adsorption of dyes onto sediment.

is due to the cooperative interaction mechanisms of the special chemical reaction and the hydrophobic effect.

\section{Effect of $\mathrm{Ca}^{2+}$ Ion on Sorption of Dyes}

The influence of $\mathrm{Ca}^{2+}$ on the adsorption of C.I. Basic Red 13 and C.I. Direct Blue 86 is shown in Fig. 7. Obviously, the sorption dependence of the two dye compounds with or without $0.1 \mathrm{~mol} / \mathrm{L}$ of $\mathrm{Ca}^{2+}$ is quite different. The addition of $\mathrm{Ca}^{2+}$ greatly reduces the sorption of C.I. Basic Red 13 on the sediment surface. The inhibition phenomenon is mainly due to the competitive adsorption of $\mathrm{Ca}^{2+}$ ion with the dye cation on the sediment surface, resulting in the decrease of available surface exchange sites. Nevertheless, the presence of $\mathrm{Ca}^{2+}$ enhances the sorption of C.I. Direct Blue 86 on the sediment. Generally, the sediment surface is charged negatively; thus the $\mathrm{Ca}^{2+}$ ion can be adsorbed directly onto the sediment interface, reducing the negative surface charge and the electrostatic repulsion between C.I. Direct Blue 86 anion and the negatively charged surface. In addition, C.I. Direct Blue 86 can form a positively charged complex with $\mathrm{Ca}^{2+}$ as follows (44):

$$
\mathrm{Ca}^{2+}+\mathrm{RSO}_{3}^{-}=\mathrm{RSO}_{3} \mathrm{Ca}^{+} \text {. }
$$

The complex cation is likely to be adsorbed on the sediment surface by electrostatic attraction or cation exchange.

\section{Effect of Organic Carbon (OC) on Sorption of Dyes}

The adsorption of organic compounds on natural particles is attributed to mineral and organic carbon fraction (46). Much research indicates that the contribution of organic carbon to the sorption of organic chemicals comes mainly from possible binding mechanisms such as the ion exchange of cationic molecules, hydrogen bonds, charge transfers, and London-van der Waals dispersion forces or the hydrophobic effect of hydrophobic molecules $(3,47,48)$. The mineral fraction in sediment plays a great part in the adsorption of organic compounds by dipole-cation interactions and coordination bonds between 


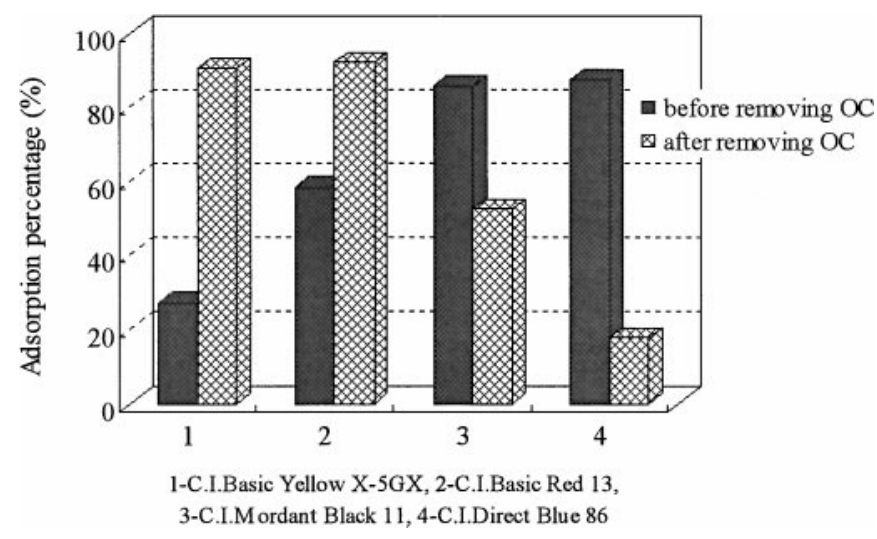

FIG. 8. Comparison of dye adsorption on the sediment after and before removing organic carbon.

exchangeable cations involved in mineral and organic cations. Generally, anionic molecules are weakly adsorbed on pure mineral fractions. Figure 8 shows a comparison of the adsorption percentages of the dye compounds on the sediment before and after removal of sediment organic carbon by $\mathrm{H}_{2} \mathrm{O}_{2}$ treatment. The organic carbon-rich sediment has a far greater adsorption percentage for C.I. Mordant Black 11 and C.I. Direct Blue 86 than the sediment with organic carbon removed. Removal of organic carbon decreases the sorption of C.I. Mordant Black 11 and C.I. Direct Blue 86 by about 25 and $40 \%$, respectively. These results strongly suggest that sediment organic carbon is an important factor controlling the sorption processes of C.I. Mordant Black 11 and C.I. Direct Blue 86. The extent of this reduction is dependent on the physicochemical properties of the dye compound.

In contrast, a significant increase in the sorption of C.I. Basic Yellow X-5GL and C.I. Basic Red 13 on the sediment is observed after removal of organic carbon. These observations show that the mineral surface sites at which cation exchange takes place play a critical role in the adsorption of the two dyes on the sediment. The oxidation of the sediment by $\mathrm{H}_{2} \mathrm{O}_{2}$ treatment can enrich mineral surfaces, and more ion-exchange sites participating in the interfacial reaction are exposed on the mineral surfaces after removal of sediment organic carbon.

\section{CONCLUSION}

The sorption of dye compounds on natural sediment represents an important control on their transport, degradation, and ultimate fate in the natural aquatic environment. This investigation has shown the potential of the sediment collected from the Qinghe River to adsorb dye compounds that may enter the river system through the disposal of municipal and industrial effluents. The potentiometric titration experiment shows that, based on the constant capacitance model, the surface protonation and deprotonation model of the sediment can successfully describe the titration data. The parameters optimized with the help of FITEQL program 2.0, such as surface acidic constants and the total concentration of surface sites for sediment in different elec- trolyte concentrations, are obtained (see Table 2). The adsorption data suggest that, for all tested dyes, sorption isotherms are fitted very well by the nonlinear Freundlich equation over the range of dye concentrations studied, and the regression coefficients $\left(R^{2}\right)$ are $0.94-0.99$. The $\mathrm{pH}$ value and ionic strength of solution show considerably different influences on the adsorption of the studied dye compounds, which are related to the physicochemical properties of these dyes. With increasing $\mathrm{pH}$ values, the sorption percentages of C.I. Mordant Black 11 and C.I. Direct Blue 86 decrease, and the sorptions of C.I. Basic Yellow X-5GL and C.I. Basic Red 13 slightly increase. Organic carbon involved in the sediment and $\mathrm{Ca}^{2+}$ ion are also the most important factors controlling the adsorption of the dyes onto the sediment. The presence of $\mathrm{Ca}^{2+}$ greatly inhibits the sorption of C.I. Basic Red 13 on the sediment surface but promotes the sorption of C.I. Direct Blue 86. The removal of organic carbon decreases the sorption of C.I. Mordant Black 11 and C.I. Direct Blue 86. In contrast, a significant increase was found in the sorption of C.I. Basic Red 13 and C.I. Basic Yellow X-5GL after removal of organic carbon.

\section{ACKNOWLEDGMENT}

This research was supported by the Natural Sciences Foundation of China (No. 20037010).

\section{REFERENCES}

1. Chiou, C. T., Mcgroddy, S. E., and Kile, D. E., Environ. Sci. Technol. 32, 264 (1998).

2. Westall, J. C., Chen, H., Zhang, W. J., and Brownawell, B. J., Environ. Sci. Technol. 33, 3110 (1999).

3. Gao, J. P., Maguhn, J., Spitzauer, P., and Kettrup, A., Wat. Res. 32 (5), 1662 (1998).

4. Kan, A. T., Fu, G., Hunter, M., Chen, W., Ward, C. H., and Tomson, M. B., Environ. Sci. Technol. 32, 892 (1998).

5. Kile, D. E., Wershaw, R. L., and Chiou, C. T., Environ. Sci. Technol. 33, 2053 (1999).

6. Pignatello, J. J., and Xing, B. S., Environ. Sci. Technol. 30, 1 (1996).

7. Luthy, R. G., Aiken, G. R., Brusseau, M. L., Cunningham, S. D., Gschwend, P. M., Pignatello, J. J., Reinhard, M., Traina, S. J., Weber, W. J., Jr., and Westall, J. C., Environ. Sci. Technol. 31, 3341 (1997).

8. Rügner, H., Kleineidam, S., and Grathwohl, P., Environ. Sci. Technol. 33, 1645 (1999).

9. Rounds, S. A., Tiffany, B. A., and Pankow, J. F., Environ. Sci. Technol. 27, 366 (1993).

10. Farrell, J., and Reinhard, M., Environ. Sci. Technol. 28, 53 (1994).

11. Werth, C. J., and Reinhard, M., Environ. Sci. Technol. 31, 697 (1997).

12. Xing, B. S., and Pignatello, J. J., Environ. Sci. Technol. 31, 792 (1997).

13. Weber, W. J., Jr., and Huang, W., Environ. Sci. Technol. 30, 881 (1996).

14. Johnson, M. D., Huang, W., Dang, Z., and Weber, W. J., Jr., Environ. Sci. Technol. 33, 1657 (1999).

15. Chiou, C. T., and Lile, D. E., Environ. Sci. Technol. 32, 792 (1998).

16. Xia, G. S., and Ball, W. P., Environ. Sci. Technol. 33, 262 (1999).

17. Benyahya, L., and Garnier, J.-M., Environ. Sci. Technol. 33, 1398 (1999).

18. Westall, J. C., Environ. Sci. Technol. 19, 193 (1985).

19. Stapleton, M. G., Sparks, D. L., and Dentel, S. K., Environ. Sci. Technol. 28, 2330 (1994).

20. Uzgiris, E. E., Edelstein, W. A., Phillipp, H. R., and Iben, I. E. T., Chemosphere 30, 177 (1995). 
21. Chiou, C. T., Peters, L. J., and Freed, V. H., Science 206, 831 (1979).

22. Karickhoff, S. W., Brown, D. S., and Scott, T. V., Water Res. 13, 241 (1979).

23. Chiou, C. T., Environ. Sci. Technol. 29, 1421 (1998).

24. Biber, M. V., and Stumm, W., Environ. Sci. Technol. 28, 3763 (1994).

25. Knight, B. A. G., and Tomlinson, T. E., J. Soil. Sci. 18, 233 (1997).

26. Undabeytia, T., and Nir, S., Environ. Sci. Technol. 33(6), 864 (1999).

27. Ukraincayk, L., and Smith, K. A., Environ. Sci. Technol. 30(6), 3167 (1996).

28. Brownawell, B. J., Chen, H., Zhang, W., and Westall, J. C., in "Organic substances and sediments in water-processes and analytical" (R. A. Baker, Ed.), Lewis Publishers: Boca Raton, FL, 1991, Vol. 2, pp 127-147.

29. Yang, X. W., Dye industry 1, 1 (1990).

30. Lin, S. H., and Peng, Ch. F., Wat. Res. 28(2), 277 (1994).

31. Meyer, V., Wat. Sci. Tech. 26(5/6), 1205 (1992).

32. Specchia, V., and Gianetto, A., Wat. Res. 18(2), 133 (1984).

33. Sun, T. H., Lin, Sh. N., Yu, Zh. M., and Chen, L., China Environ. Sci. 11(2), 138 (1991).

34. Kuo, W. G., Wat. Res. 26(7), 881 (1992).

35. Choi, W., Termin, A., and Hoffmann, M. R., J. Phys. Chem. 98, 13669 (1994).

36. Carraway, E. R., Hoffmann, A. J., and Hoffmann, M. R., Environ. Sci. Technol. 28, 786 (1994).
37. Reynaldo, D. B., Kimberly, A. G., and Krista, A., Wat. Res. 29(5), 1243 (1995).

38. Stadler, M., and Schindler, P. W., Clays Clay Min. 41, 556 (1993).

39. Du, Q., Sun, Z. X., Forsling, W., and Tang, H. X., J. Colloid Interface Sci. 197, 221 (1997).

40. Ludwig, C., and Schindler, P. W., J. Colloid Interface Sci. 169, 284 (1995).

41. Davis, L. A., and Kent, D. B., in "Reviews in Mineralogy: Vol. 23, MineralWater Interface Geochemistry" (M. F. Hochella, Jr. and A. F. White, Eds.), pp. 177-260. Mineralogical Society of America, Madison, WI, 1990.

42. Fu, G. M., and Allen, H. E., Wat. Res. 26(2), 225 (1992).

43. Westall, J. C., FITEQL: A program for the Determination of Chemical Equilibrium Constants from Experimental Data, Rep. 82-01. Depart. of Chemistry, Oregon State Univ. Corvallis, 1982.

44. Weatall, J. C., Chen, H., Zhang, W. J., and Brownawell, B. J., Environ. Sci. Technol. 33, 3110 (1999).

45. Inoue, K., Kaneko, K., and Yoshida, M., Soil Sci. Plant Nutr. 24, 91 (1978).

46. Calvet, R., Environ. Health Perspect. 83, 145 (1998).

47. Chiou, C. T., Shoup, T. D., and Porter, P. E., Org. Geochim. 8, 9 (1985).

48. Chiou, C. T., Malcom, R. L., Brinton, T. I., and Kile, D. E., Environ. Sci. Technol. 20, 502 (1986). 